\title{
Temperature and wavelength dependent refractive index equations for MgO-doped congruent and stoichiometric $\mathrm{LiNbO}_{3}$
}

\author{
O. Gayer · Z. Sacks · E. Galun • A. Arie
}

Published online: 26 November 2008

(C) Springer-Verlag 2008

Erratum to: Appl. Phys. B (2008) 91, 343

DOI 10.1007/s00340-008-2998-2

Unfortunately, an error occurred in Fig. 3. The corrected figure is given here.

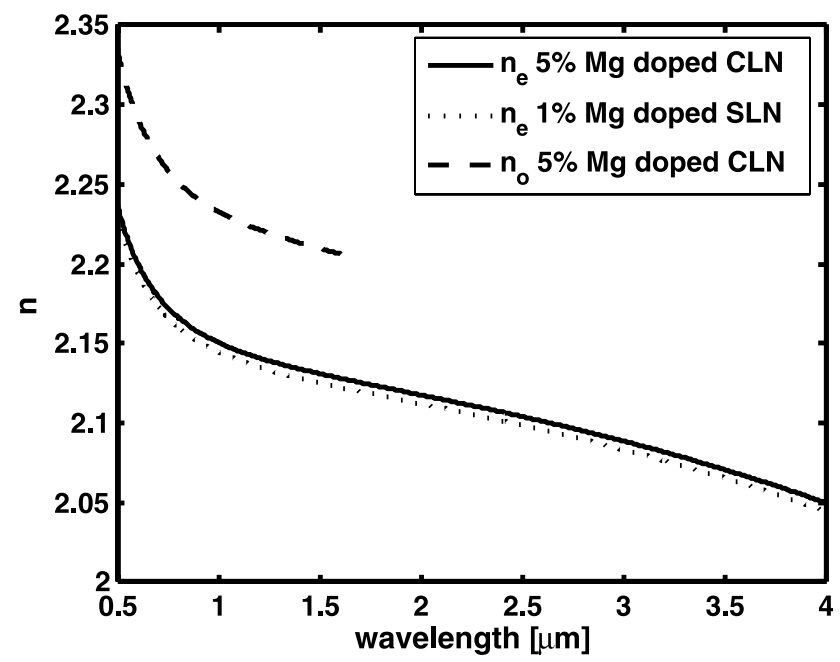

Fig. 3 Room temperature refractive index curves for 5\% Mg-doped $\operatorname{CLN}\left(n_{\mathrm{e}}\right.$ and $\left.n_{\mathrm{o}}\right)$, and for $1 \% \mathrm{Mg}$-doped SLN $\left(n_{\mathrm{e}}\right)$, according to the new Sellmeier parameters given in Table 1

The online version of the original paper can be found under doi:10.1007/s00340-008-2998-2.

\section{O. Gayer $(\bowtie) \cdot$ A. Arie}

Department of Physical Electronics, School of Electrical Engineering, Tel-Aviv University, Tel-Aviv 69978, Israel

e-mail: gayerofe@post.tau.ac.il 